\title{
MEASUREMENT OF DIRECTIONAL THERMAL INFRARED EMISSIVITY OF VEGETATION AND SOILS
}

J.M. Norman

Department of Soil Science, University of Wisconsin, Madison, WI

L.K. Balick

E G \& G, Las Vegas, NV

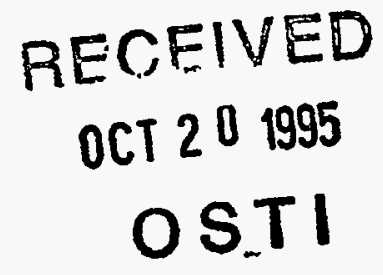

\section{Abstract}

A new method has been developed for measuring directional thermal emissivity as a function of view angle for plant canopies and soils using two infrared thermometers each sensitive to a different wavelength band. By calibrating the two infrared thermometers to $0.1 \mathrm{C}$ consistency, canopy directional emissivity can be estimated with typical errors less than 0.005 in the 8-14 um wavelength band, depending on clarity of the sky and corrections for $\mathrm{CO}_{2}$ absorption by the atmosphere. A theoretical justification for the method is developed along with an error analysis. Laboratory measurements were used to develop corrections for $\mathrm{CO}_{2}$ absorption and a field calibration method is used to obtain the necessary $0.1 \mathrm{C}$ consistency for relatively low cost infrared thermometers. The emissivity of alfalfa $(L A I=2.5)$ and corn (LAI=3.2) was near 0.995 and independent of view angle. Individual corn leaves had an emissivity of 0.97 . A wheat (LAI=3.0) canopy had an emissivity of 0.985 at nadir and 0.975 at 75 degree view angle. The canopy emissivity values tend to be higher than values in the literature, and are useful for converting infrared thermometer measurements to kinetic temperature and interpreting satellite thermal observations.

\section{INTRODUCTION}

Indirect measurements of thermal radiance are useful for estimating the temperature of complex surfaces such as soils and vegetation canopies. In fact, in the case of vegetation, infrared observations probably represent the only practical means for observing something near the "surface" temperature. The difficulties associated with inferring vegetation temperature from infrared observations have been discussed in detail in Norman et al. (1994) and will not be repeated here. In this paper we are concerned with the thermal emissivity of soils and vegetation because this quantity must be known before indirect thermal radiance observations can be converted into a kinetic temperature.

An infrared thermometer (IRT) measures the thermal radiance in some limited wavelength band that is coming from a surface that is within its field of view. Assuming the surface is a perfect black body diffuse emitter, the relation between radiance and target temperature is 


\section{DISCLAIMER}

This report was prepared as an account of work sponsored by an agency of the United States Government. Neither the United States Government nor any agency thereof, nor any of their employees, makes any warranty, express or implied, or assumes any legal liability or responsibility for the accuracy, completeness, or usefulness of any information, apparatus, product, or process disclosed, or represents that its use would not infringe privately owned rights. Reference herein to any specific commercial product, process, or service by trade name, trademark, manufacturer, or otherwise does not necessarily constitute or imply its endorsement, recommendation, or favoring by the United States Government or any agency thereof. The views and opinions of authors expressed herein do not necessarily state or reflect those of the United States Government or any agency thereof. 


\section{DISCLAIMER}

Portions of this document may be illegible in electronic image products. Images are produced from the best available original document. 


$$
R\left(T_{M}\right)=\int_{\lambda_{1}}^{\lambda_{2}} \frac{C_{1}}{\pi \lambda^{5}\left[\exp \left(\frac{C_{2}}{\lambda T_{H}}\right)-1\right]} d \lambda
$$

where $\lambda$ is the wavelength in micrometers, $\lambda_{1}$ and $\lambda_{2}$ are the lower and upper wavelengths of sensitivity of the infrared thermometer, $T_{M}$ is termed the brightness temperature, $R\left(T_{M}\right)$ is the radiance measured by the IRT, $C_{2}=3.7404 \mathrm{~W} \mathrm{~m}^{-2} \mu^{-1}$, and $\mathrm{C}_{1}=14387 \mu \mathrm{K}$. Inversion of Eq. (l) provides an estimate of the brightness temperature given an estimate of the thermal radiance from the IRT. Frequently the inverse of Eq. (1) is replaced by the fourth root of the radiance times a constant. This is a reasonable approximation in the 8-14 um wavelength band over a limited range of temperatures. Conversion of this brightness temperature to an effective thermodynamic temperature requires correction for the sky irradiance that is reflected by the canopy because the canopy emissivity is less than unity. This is discussed later in the theory section. If the sky irradiance is assumed negligible, then an uncertainty of 0.01 in canopy emissivity corresponds to a difference between brightness and thermodynamic temperatures of about $0.7 \mathrm{C}$; for a surface with emissivity of 0.95 , the brightness and thermodynamic temperatures would be different by 3.7 C. Thus surface emissivities are required for interpretation of IRT measurements.

Another consideration with infrared thermometer measurements is that ground-based IRT's generally are sensitive to the 8-14 um wavelength band and satellite sensors are sensitive to the 10-12 um band. Most natural surfaces have higher emissivities in the 10-12 um band than in the 8-14 um band.

The usefulness of infrared thermometry has long been appreciated and Jackson (1981) provides an excellent review. The early work of Fuchs and Tanner (1966) set forth the principles and practices associated with the use of IRT's over vegetation. They proposed a method for measuring vegetation-canopy emissivity from the nadir direction that is still used today. They obtained nadir emissivity estimates of $0.975 \pm 0.005$ for sudangrass and alfalfa. Blad and Rosenberg (1976) obtained an estimate of nadir emissivity for alfalfa of 0.973 using the same method. However the method of Fuchs and Tanner (1966) has not been used to measure directional emissivities of vegetation because of practical difficulties. Therefore, apparently, few measurements of directional thermal emissivity of vegetation have been attempted, even though directional effects of IRT measurements have long been appreciated (Fuchs et al., 1967). The one exception is the work of Becker et al. (1985), who describe a laboratory method, which could be adapted to the field, for measuring the thermal bidirectional reflectance distribution function for soils using a $\mathrm{CO}_{2}$ laser as a source. A "box" method was developed by Buettner and Kern (1965) for measuring nadir emissivity of relatively smooth surfaces.

Remote estimates of vegetation and soil emissivities have been obtained from measurements made in several narrow wavelength bands within the 8-14 um atmospheric window. Kealy and Hook (1993) evaluate several possible assumptions that must be made to obtain emissivity from spectral measurements.

The method described in this paper is an attempt to evaluate emissivity using IRT measurements in two wavelength bands; one band for which the emissivity is desired such as 814 or 10-12 um, and a second band, such as $14-22 \mu \mathrm{m}$, where the atmosphere is relatively opaque 
because of absorption of thermal radiation by $\mathrm{CO}_{2}$ absorption. Measurements are made at a range of incidence angles using four IRTs; two facing the surface and two pointed toward the sky. The IRT measurements in the 14-22 um wavelength band are used to estimate the thermodynamic temperature of the surface after minor corrections for $\mathrm{CO}_{2}$ absorption, and the 8-14 um measurements are used to evaluate the sky irradiance and surface radiance. This paper contains a discussion of some theory and errors, along with instrument calibration, procedures and field results.

\section{THEORY}

When a narrow field-of-view (FOV) IRT is pointed toward a canopy at a particular angle, the measured radiance is a combination of emission from the canopy and reflection of incident, hemispherical flux (incident thermal irradiance) from the sky into the direction of the IRT. Thus the relevant reflectance, is the hemispherical-directional reflectance; the first modifier (hemispherical) referring to the angular distribution of the incident radiation and the second modifier (directional) referring to the reflected direction (Nicodemus, et al., 1977). Emission from a surface does not depend on incident radiation so emissivity has only a single modifier (directional or hemispherical). The relation between the directional emissivity and the hemispherical-directional reflectance is given by

$$
\epsilon(\theta, \phi)=1-\rho(\theta, \phi)
$$

for a narrow wavelength interval, where $\theta$ is the zenith angle and $\phi$ the azimuth angle. For a broad wavelength band with strong spectral dependencies of the incident radiation and surface radiative properties, Eq.(2) may not hold (Nicodemus, 1965). However, for vegetation exposed to atmospheric radiation, which has a relatively flat wavelength dependency from 8-14 um except for a narrow absorption band near 9.5 um for ozone, Eq.(2) is a reasonable approximation in the 8-14 um wavelength band. The radiance sensed by a directional radiometer can be estimated from a combination of emitted and reflected radiation within a wavelength band denoted by the subscript 1 , which could refer to $8-14$ um or 10-12 um:

$$
R_{m, i}(\theta, \phi)=\epsilon_{1}(\theta, \phi) R_{c, i}(\theta, \phi)+\left[1-\epsilon_{1}(\theta, \phi)\right] \frac{F_{s, 1}}{\pi}
$$

Where $R_{m, l}(\theta, \phi)$ is the radiance from the surface measured by an IRT in the zenith direction $\theta$ and azimuth direction $\phi, R_{c, 1}$ is the black body emission from the canopy based on the canopy kinetic temperature $\left(T_{c, 1}(\theta, \phi)\right)$, and $F_{s, 1}$ is the thermal flux density incident on the canopy from the complete hemisphere of the sky. Although $R_{c, 1}(\theta, \phi)$ may depend on angle when vegetation 
and soil are at different temperatures, Eq. (3) is most accurate when this angular dependence is small and the soil-vegetation system is near isothermal such as at night. The energy-based quantities in Eq. (3) can be related to temperatures using the black body relation in Eq.(1) as follows:

$$
\begin{gathered}
R_{m, 1}(\theta, \phi)=\int_{1_{1}}^{\lambda_{2}} \frac{f_{1}(\lambda) C_{1}}{\pi \lambda^{5}\left[\exp \left(\frac{C_{2}}{\lambda T_{M, 1}(\theta, \phi)}\right)-1\right]} d \lambda \\
R_{c, 1}(\theta, \phi)=\int_{1_{1} \pi \lambda^{5}\left[\exp \left(\frac{f_{1}(\lambda) C_{1}}{\lambda T_{c}(\theta, \phi)}\right)-1\right]}^{\lambda_{2}} d \lambda \\
\quad= \\
F_{s, 1}=\int_{0}^{2 \pi} \int_{0}^{\frac{\pi}{2}} \int_{L_{1}}^{\lambda_{2}} \frac{f_{1}(\lambda) C_{1} \sin (\theta) \cos (\theta)}{\pi \lambda^{5}\left[\exp \left(\frac{C_{2}}{\lambda T_{s, 1}(\theta, \phi)}\right)-1\right]} d \lambda d \theta d \phi
\end{gathered}
$$

where $T_{M, 1}$ is the brightness temperature of the canopy, $T_{c}$ is the kinetic temperature of the canopy from a particular angle and is not dependent on the wavelength band, $T_{s, 1}$ is the brightness temperature of the sky, and $f_{1}(\lambda)$ is the relative response of the IRT detector in wavelength band 1 (for example 8-14 $\mu \mathrm{m}$ ). If an IRT is used to make the directional measurements, then Eqs.(4)(6) are used to obtain radiances in Eq.(3). Equation (3) could be solved for $\varepsilon(\theta, \phi)$, but this is of little use because $R_{c, 1}$ (or $T_{c, 1}$ ) can not be determined. If IRT measurements could be made in a second wavelength band where the sky had a brightness temperature near to that of the surface, but atmospheric transparency was high enough so that surface temperature measurements were not unduly influenced by the air path between the IRT and the canopy; then the canopy would effectively be in a black body cavity in this wavelength band and the brightness temperature in this second wavelength band would be near to the canopy kinetic temperature. Unfortunately this second equation also introduces a second emissivity so the application of this idea requires some effort. A second equation like Eq.(3) can be written for the second wavelength band (for example 14-22 um):

$$
R_{m, 2}(\theta, \phi)=\epsilon_{2}(\theta, \phi) R_{c, 2}(\theta, \phi)+\left[1-\epsilon_{2}(\theta, \phi)\right] \frac{F_{s, 2}}{\pi}
$$

Subtracting Eq.(7) from Eq.(3) and solving for $\varepsilon_{1}$ yields

If $\varepsilon_{1}=\varepsilon_{2}$, then 


$$
\epsilon_{1}(\theta, \phi)=\frac{R_{m, 1}(\theta, \phi)-R_{m, 2}(\theta, \phi)-\epsilon_{2}(\theta, \phi)\left[\frac{F_{s, 2}}{\pi}-R_{c, 2}(\theta, \phi)\right]-\frac{F_{s, 1}}{\pi}+\frac{F_{s, 2}}{\pi}}{R_{c, 1}(\theta, \phi)-\frac{F_{s, 1}}{\pi}}
$$

$$
\epsilon_{1}(\theta, \phi)=\frac{R_{m, 1}(\theta, \phi)-R_{m, 2}(\theta, \phi)-\frac{F_{s, 1}}{\pi}+\frac{F_{s, 2}}{\pi}}{R_{c, 1}(\theta, \phi)-\frac{F_{s, 1}}{\pi}+\frac{F_{s, 2}}{\pi}-R_{c, 2}(\theta, \phi)}
$$

If the two IRT instruments are calibrated to indicate the same temperature when they view a single black body, and this is done over their entire temperature range; then the term $R_{c, 1}(\theta, \phi)$ $R_{c, 2}(\theta, \phi)$ is zero and $\varepsilon_{1}$ can be estimated from the following equation:

$$
\epsilon_{1}(\theta, \phi)=1-\left[\frac{T_{m, 1}^{4}(\theta, \phi)-T_{m, 2}^{4}(\theta, \phi)}{T_{s, 1}^{4}-T_{s, 2}^{4}}\right]
$$

Clearly the error caused by $\varepsilon_{1} \neq \varepsilon_{2}$ will be smaller if $T_{c, 2} \approx T_{s, 2}$.

The accuracy of the approximations made in this development are evaluated in the next section.

\section{ERROR ANALYSIS}

Several factors enter into an error analysis of this sky-cavity method for estimating vegetation emissivity: 1) Errors from approximating the radiances with a constant times $T^{4}, 2$ ) errors from $\varepsilon_{1} \neq \varepsilon_{2}, 3$ ) uncertainties from instrument measurement errors, and 4) absorption/emission of thermal radiation by $\mathrm{CO}_{2}$ in the path between the IRT and target.

Errors associated with using Eq.(10) can be evaluated by comparing results from it with results from Eq.(8). Given values of $T_{s, 1}, T_{s, 2}, T_{c, 1}, T_{c, 2}$, we can calculate radiances from Eqs.(5) and (6); Then $R_{m, 1}$ and $R_{m, 2}$ values can be estimated from Eqs.(3) and (7) with given values of $\varepsilon_{1}$ and $\varepsilon_{2}$. Values of $T_{m, 1}$ and $T_{m, 2}$ are obtained by inverting Eq.(4) and its equivalent in wavelength band 2 ; these are taken to be the temperatures that would be measured by an IRT with no measurement errors. The values of $T_{m, 1}, T_{m, 2}, T_{s, 1}$ and $T_{s, 2}$ then are used in Eq.(10) to estimate $\varepsilon_{1}$, which can be compared to the given value that was input. Table 1 contains the maximum error encountered by using Eq. (10) in either the $8-14 \mu \mathrm{m}$ or $10-12 \mu \mathrm{m}$ wavebands if $\varepsilon_{1}=\varepsilon_{2}$. Clearly the errors associated with this approximation are small, indeed.

The assumption that $\varepsilon_{1}=\varepsilon_{2}\left(\varepsilon_{8.14}=\varepsilon_{14.22}\right.$ or $\left.\varepsilon_{10.12}=\varepsilon_{14-22}\right)$ is reasonable but needs to be evaluated to determine its importance. The magnitude of this error depends on the temperature difference between the sky and the canopy in the 14-22 $\mu \mathrm{m}$ wavelength band $\left(T_{s, 2}-T_{c, 2}\right)$. When $\left(T_{3,2}-T_{c, 2}\right)$ is zero, no error is caused by the difference in 8-14 and 14-22 $\mu \mathrm{m}$ emissivities. Figure 1 contains a graph of the maximum error in $\varepsilon_{1}$ caused by a 0.01 difference between $\varepsilon_{1}$ and $\varepsilon_{2}$ 
for a range of values $T_{s, 1}-T_{c, 2}$, which represents the clearness of the sky. Fortunately this skycavity method makes it easy to obtain measurements at several values of $T_{s, 1}-T_{c, 2}$ so the magnitude of $\varepsilon_{1}-\varepsilon_{2}$ can be reasonably approximated by iteratively applying Eqs. (10) and (8) with several data sets. From the results in Fig. 1, this method may be suitable for a range of skyminus-canopy temperatures from -90 to $-30 \mathrm{C}$.

The most important error associated with this sky-cavity method is from the measurement accuracy of the infrared thermometers. A single infrared radiometer with multiple filters can achieve consistency of $0.1 \mathrm{C}$ or better. By consistency here we mean that two measurements of temperature in different wavelength bands would yield the same temperature within $0.1 \mathrm{C}$ for the same surface even though the absolute accuracy may only be $0.5 \mathrm{C}$. With several IRTs sensitive to different wavelength bands, a consistent calibration precision of $0.1 \mathrm{C}$ requires considerable effort but is possible with a suitable field calibration device. The one possible exception to a 0.1 $\mathrm{C}$ consistency measurement is the sky temperature in the atmospheric window region $\left(\mathrm{T}_{\mathrm{s}, 1}\right)$. Unless exceptional calibration facilities are available so that each individual IRT can be exposed to an accurate black-body target with a temperature 20 to $90 \mathrm{C}$ below the temperature of the IRT, the uncertainty in this sky measurement is between 0.5 and $2 \mathrm{C}$.

A maximum error in $\varepsilon_{1}$ can be estimated from Eq.(8) by choosing the sign of the error in the various temperatures so as to maximize the error in $\varepsilon_{1}$. Figure 2 contains a prediction of the maximum error in $\varepsilon_{1}$ from a $0.1 \mathrm{C}$ error in $\mathrm{T}_{\mathrm{s}, 2}, \mathrm{~T}_{\mathrm{m}, 1}, \mathrm{~T}_{\mathrm{m}, 2}$ and a $2 \mathrm{C}$ error in $\mathrm{T}_{\mathrm{s}, 1}$. The combined contribution of this temperature error and an error of a 0.01 in $\varepsilon_{1}-\varepsilon_{2}$ for $T_{s, 2}-T_{c, 2}=-5 C$ is included in Fig. 3.

The final error can arise because 14-22 um infrared radiation is absorbed by $\mathrm{CO}_{2}$ in the air between the IRT and the target. If the air temperature and the target temperature are the same, then no error occurs. If the air and target are at different temperatures, then the error depends on the temperature difference between the target and the air, the $\mathrm{CO}_{2}$ concentration, and the path length.

An apparatus was constructed in the laboratory to measure the effect of $\mathrm{CO}_{2}$ absorption from the intervening path between the IRT and the target. The apparatus was an upright, $1.5 \mathrm{~m}$ tall aluminum cylinder ( $197 \mathrm{~mm}$ diameter) with a heated anodized aluminum plate ( $12 \mathrm{~mm}$ thick) at the bottom, a mounting platform for an IRT, two ports for air entry at a height of $35 \mathrm{~mm}$ above the heated base of the $1.5 \mathrm{~m}$ tube, and an exit port for the air at the IRT platform. The inside face of the IRT platform and the inside of the aluminum tube were covered with aluminum foil to minimize emission from these walls. The $\mathrm{CO}_{2}$ concentration within this apparatus was monitored with a LICOR (Lincoln, NE), LI-6262 infrared gas analyzer from a sampling tube that extracted about $1 / 2$ liter $/ \mathrm{min}$ at a height of $0.71 \mathrm{~m}$ above the heated bottom plate. The temperature of the air in the $1.5-\mathrm{m}$ tube was measured with two, $0.075 \mathrm{~mm}$ chromel-constantan thermocouples mounted at 0.10 and $0.70 \mathrm{~m}$ above the heated base, and the temperature of the heated base was measured with two $0.075 \mathrm{~mm}$ chromel-constantan thermocouples that were glued to the aluminum surface. In addition the plate surface temperature was measured with IRT's sensitive to both $8-14 \mu \mathrm{m}$ and $14-22 \mu \mathrm{m}$. The end of the $1.5 \mathrm{~m}$ tube was insulated from the anodized aluminum base plate. Flow through the two air-entry ports near the base of the $1.5-\mathrm{m}$ tube was maintained at $35 \mathrm{liters} / \mathrm{min}$ and the $\mathrm{CO}_{2}$ concentration varied from zero to 3700 $\mu \mathrm{mol} / \mathrm{mol}$. The temperature of the heated anodized aluminum base plate was controlled at $33 \mathrm{C}$ and was maintained at $8.0 \mathrm{C}$ above the temperature of the air in the tube. The distance from the 
lens of the IRT to the heated anodized aluminum plate was $0.87 \mathrm{~m}$.

The results from this laboratory experiment are shown in Fig. 4. The temperature of the heated, anodized plate that was measured with the IRT sensitive to $8-14 \mu \mathrm{m}$ is included on this graph. This temperature should not be dependent on absorption by $\mathrm{CO}_{2}$; furthermore, the agreement with the temperature from the surface thermocouple verifies that the experimental setup was suitable for accurate infrared observations. Both infrared thermometers were calibrated using water in insulated containers at the same temperature as the heated plate. The temperature correction to the raw measured target temperature $(\Delta \mathrm{T})$ can be estimated from

$$
\begin{gathered}
\Delta T=\frac{29.3 \times 10^{-6} C_{\text {aIr }} s\left(T_{\text {target }}-T_{\text {aIr }}\right)}{1-29.3 \times 10^{-6} C_{\text {oir }} s} \\
=
\end{gathered}
$$

where $s(m)$ is the path length between the sensor and target, $C_{a i r}(\mu \mathrm{mol} / \mathrm{mol})$ is the path-averaged $\mathrm{CO}_{2}$ concentration, $\mathrm{T}_{\text {target }}$ is the raw measured target temperature, and $\mathrm{T}_{\mathrm{air}}$ is the path-averaged air temperature. Thus, if $\mathrm{T}_{\mathrm{air}}=20 \mathrm{C}, \mathrm{T}_{\text {target }}=17 \mathrm{C}, \mathrm{C}_{\mathrm{air}}=370 \mu \mathrm{mol} / \mathrm{mol}$, and $\mathrm{s}=2 \mathrm{~m}$, then the corrected target temperature is 16.93 , with a resulting correction of $-0.07 \mathrm{C}$. For path lengths under one meter this correction is likely to be negligible, even for relatively high night time $\mathrm{CO}_{2}$ concentrations. For normal ambient $\mathrm{CO}_{2}$ concentrations and temperature differences between vegetation and air; this correction will normally be less than $0.3 \mathrm{C}$ and have uncertainties of less than $0.05 \mathrm{C}$ for path lengths up to $10 \mathrm{~m}$.

\section{INSTRUMENTATION}

The instrumentation required to make these measurements of directional emissivity can be considered in three groups: 1) The infrared thermometers (IRT), 2) calibration of the IRTs in the field, and 3) directional mounting equipment for the IRTs.

\section{Infrared Thermometers}

The IRTs used for this study are Everest 4000 ALCS, which are linearized and have a digital RS232 output. Two of the instruments were the standard variety with wavelength sensitivity from $8-14 \mathrm{um}$, and two were special orders with filters that provided sensitivity from $14-22 \mathrm{um}$. The nominal field of view was specified to be 4 degrees. Figure 5 contains angular responses of 8-14 and 14-22 $\mu \mathrm{m}$ instruments that were obtained using a hot point source. Clearly from Fig. 5 , when precise calibrations are required, the reference surface should occupy a double angle of view of about 15 degrees.

\section{Calibration}

Calibration of the IRTs is critical in order to achieve the consistency required by the method. Calibration is done in the field during measurements using a slightly modified version of the calibrator that Everest supplies (Model 1000). A cylindrical cavity $100 \mathrm{~mm}$ in diameter and 150 
$\mathrm{mm}$ long is lined with aluminum foil and attached over the reference black body surface. An IRT is placed at a hole in one end of this cavity so its lens is $190 \mathrm{~mm}$ from the reference surface (The end of the IRT is $140 \mathrm{~mm}$ from the reference surface). If this modified calibrator is placed near the top of the canopy during measurement times in late afternoon (shaded from the sun) and early evening, after about one hour it will normally remain within $1 \mathrm{C}$ of the canopy temperature. Based on the characteristics of the IRTs, this should provide an absolute accuracy of $0.1 \mathrm{C}$ in the IRT calibration. If the sky temperature is near the canopy temperature in the $14-22 \mathrm{um}$ wavelength band, a condition that is desired and usually easy to obtain, than similar accuracy will be obtained for this sky temperature. Because of the characteristics of the IRTs, if the calibrator is $3 \mathrm{C}$ different from the canopy temperature, which is a rare occurrence, the absolute error may be $0.3 \mathrm{C}$; but the $8-14$ and $14-22$ um canopy temperatures, which are the most critical for accurate emmissivity measurements, will be consistent within less than $0.1 \mathrm{C}$.

The IRTs were calibrated over a wide range of target temperatures in the laboratory at an ambient temperature of $25 \mathrm{C}$. Figure 6 contains results from these calibrations for two IRTs that are sensitive to $8-14 \mu \mathrm{m}$. The 14-22 $\mu \mathrm{m}$ IRT's only need be calibrated over a limited temperature range. Clearly obtaining $0.1 \mathrm{C}$ accuracy from instruments such as these is a challenge, but it can be done. The parallel behavior of all the instruments tested makes it possible to obtain consistency of $0.1 \mathrm{C}$ when accuracies are only $0.5 \mathrm{C}$. Thus consistency of $0.1 \mathrm{C}$ can be obtained between $8-14$ and $14-22$ um canopy temperatures with a passive calibrator in the field. More accurate measurements can be obtained with an active Peltier calibrator, which can provide an approximate black body at what ever temperature is desired. However this adds considerable cost and complexity to the measurement procedure. Such a calibrator has been built and the most challenging task is obtaining absolute accuracy for both $8-14$ and $14-22$ um wavelength measurements.

\section{Directional Mounting Equipment}

Two kinds of mounting assemblies have been used to obtain the directional temperature measurements. For soils and canopies less than a meter in height, the sensors are mounted on an arm that pivots at the surface and swings through an arc so that the same spot on the surface is viewed from all directions. The measurements on soil, wheat and alfalfa were made with this kind of apparatus. Canopies taller than a meter can be measured by using a servo system to pivot the IRT mount through a range of angles. Unfortunately this results in the IRTs viewing a different spot on the surface at each angle so more spatial sampling is required to average out variations. This system also results in path length changes with angle so that $\mathrm{CO}_{2}$ corrections may be different for different angles. The measurements in corn were made with this kind of apparatus.

The mounting assembly for soils and short canopies had a pivoting arm one meter long that could be positioned at fixed angles of $0,15,30,45,60,75$ degrees from nadir on both sides of nadir; that is, observations could be made at two azimuth angles without moving the apparatus. The two horizontal arms holding the IRT's, two IRT's pointed skyward and two pointed toward the target, could be quickly removed with locking pins so that the pivoting arm could be moved through nadir to obtain the second azimuth angle of observations. The base of the pivoting arm could be positioned over a range of heights from the soil surface to one meter above the soil 
surface by designing the entire pivot-arm apparatus to slide over a mounting post that was anchored in the ground with a $30-\mathrm{cm}$ spike.

The mounting assembly for taller crops was designed to be attached to the post of a triangular tower. A bracket was attached to a horizontal shaft to hold the four IRT's, two pointed skyward and two pointed toward the target. The horizontal shaft was attached to a servo that could rotate the shaft and position it within an accuracy of one degree. The servo, shaft and IRT bracket were attached to a platform that could slide about $0.4 \mathrm{~m}$ on the tower mount so that measurements could be made up to $1.5 \mathrm{~m}$ from the tower and the IRT's moved back toward the tower for easy calibration with black body references. In addition, when measurements were made over a row crop such as corn, the IRT measurements could be made directly over the row of plants or between rows by moving this slide without having to adjust the tower mount.

\section{FIELD SITES AND MEASUUREMENTS}

\section{Field Sites}

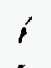

Field measurements were made at two locations: 1) Maricopa Agricultural Center, which is operated by the USDA/ARS near Phoenix, Arizona, and 2) the West Madison Agricultural Research Center operated by the University of Wisconsin near Madison, Wisconsin.

At Maricopa measurements were made on alfalfa and wheat at two locations in each field. The alfalfa was very uniform, $0.40 \pm 0.05 \mathrm{~m}$ tall and leaf area index (LAI) of $2.5 \pm 0.2$, and measurements were made at location 1 between 2000 and 2100 and location 2 between 2100 and 2200 on Sept. 8, 1991. The wheat field was more heterogeneous with location 1 being $0.5 \mathrm{~m}$ tall and having $\mathrm{LAI}=2.2$, and location 2 being $1 \mathrm{~m}$ tall having $\mathrm{LAI}=3.8$. Carbon dioxide concentration measurements varied from 360 to $500 \mu \mathrm{mol} / \mathrm{mol}$ at a height of $0.5 \mathrm{~m}$ above the canopies, and no condensation occurred during measurements. Nadir measurements of the emissivity of bare, packed soil were made on Sept. 9, 1994 and found to vary between 0.939 and 0.954 from six measurements.

The measurements at the West Madison location included a corn canopy, individual corn leaves and a bare soil. The corn canopy measurements were made on September 3, 1992, the canopy was $2.5 \mathrm{~m}$ tall, had LAI=3.2, and the IRT instruments were mounted $2.0 \mathrm{~m}$ above the top of the tassels. For purposes of $\mathrm{CO}_{2}$ path absorption, the nadir distance was taken as $2.5 \mathrm{~m}$ to represent the distance to the most dense part of the canopy. Measurements were made with the IRT's centered on the row and centered between rows for comparison. The $\mathrm{CO}_{2}$ concentration of the air one meter above the canopy varied from 450 to $550 \mu \mathrm{mol} / \mathrm{mol}$ and the air temperature remained within $1 \mathrm{C}$ of the $14-22 \mu \mathrm{m}$ canopy temperature. Thus corrections for $\mathrm{CO}_{2}$ path absorption varied from $0.04 \mathrm{C}$ at nadir to 0.08 at 60 degrees to 0.17 at 75 degrees view angle. Neglecting this $\mathrm{CO}_{2}$ path absorption effect would result in too low an emissivity by 0.002 at nadir, 0.005 at 60 degrees and 0.01 at 75 degrees view angle. Measurements on individual corn leaves from a nadir view resulted in emissivity values that varied from 0.961 to 0.973 with a mean of 0.967 . These measurements were made on the top and bottom of five different leaves. The soil measurements were made on October 10,1993 on a recently tilled silt loam soil that had aggregates two to five centimeters in size and the surface was somewhat moist. Measurements were made at two locations. 


\section{Measurement Procedure}

The measurement procedure begins with a black body calibration on all four IRT's. Measurements then are made in the following order: 1) nadir, 2) $\left.15^{\circ}, 3\right) 30^{\circ}$, 4) nadir, 5) $45^{\circ}, 6$ ) $\left.60^{\circ}, 7\right)$ nadir, 8) $\left.75^{\circ}, 9\right)$ nadir. A black body calibration is then done following this series of measurements. This whole procedure is repeated for the second azimuth 180 degrees away from the first. This procedure permits adjustment for slow changes in canopy and sky temperatures that can occur over five or 10 minutes by having measurements at each angle made within about one-half minute of a measurement at nadir. Typically this slow drift in canopy temperature is less than 0.5 to $1 \mathrm{C}$ during a complete set of measurements at two view azimuths.

\section{RESULTS}

The results for the alfalfa and wheat canopies at Maricopa Agricultural Center are shown in Fig. 7. The curves are the averáged result from two wheat canopies and two alfalfa canopies. Table 2 contains a summary of conditions under which the field measurements were taken. The results of measurements made at the West Madison Agricultural farm for corn and a soil are shown in Fig. 8. The effect of the path absorption by $\mathrm{CO}_{2}$ on the measurements of corn canopy emissivity at high zenith angles is significant. The corn measurements are an average of eight sets of observations parallel to the corn rows with four sets taken with the IRTs aimed between rows and four set in rows. The difference between in-row and between-row emissivities is less than 0.005 .

\section{CONCLUSIONS}

A sky cavity method is introduced in this paper to measure the directional thermal emissivity of vegetation and soils. An error analysis suggests that this method provides estimates of directional emissivity with maximum errors less than 0.01 and typical errors less than 0.005 . Errors are larger in the 10-12 $\mu \mathrm{m}$ wavelength band than the 8-14 $\mu \mathrm{m}$ band because temperature to the fourth power does not approximate emission in 10-12 $\mu \mathrm{m}$ band as closely as in the 8-14 $\mu \mathrm{m}$ band. Some effort at determining the power of temperature that more closely approximates emission in the 10-12 $\mu \mathrm{m}$ band would likely reduce these errors. This sky cavity method also could be used to obtain high resolution thermal emissivity spectra for canopies and soils with a High Resolution Interferometer Sounder.

\section{ACKNOWLEDGEMENTS}

acknowledge the

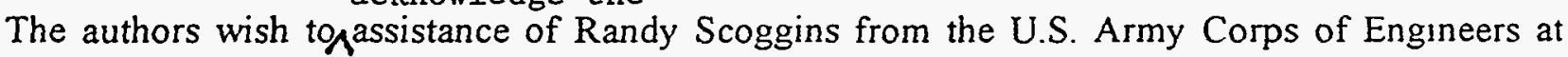
Vicksburg, Miss. We also acknowledge the funding support from NASA under Grant Number NAGW-2536 through the Science Division of the Mission to Planet Earth Office. The authors developed this method of measuring directional emissivity of vegetation after a discussion at the 1990 meeting of the American Society of Agronomy that included Dr. Paul Pinter of the USDA/ARS, Phoenix, AZ. We also thank Scott Castello for assisting in lab experiments.

\section{REFERENCES}


Becker, F., Ramanantsizehena, P. and Stoll, M.C. (1985) Angular variation of the bidirectional reflectance of bare soils in the thermal infrared band. Applied Optics 24:365-375.

Blad, B.L. and Rosenberg, N,J. (1976) Measurement of crop temperature by leaf thermocouple, infrared thermometry, and remotely sensed thermal imagery, Agron. J. 68:635-641.

Buettner, K.J.K. and Kern C.D. (1965) The determination of infrared emissivities of terrestrial surfaces, J. Geophys. Res. 70:1329-1337.

Fuchs, M., Kanemasu, E.T., Kerr, J.P. and Tanner, C.B. (1967) Effect of viewing angle on canopy temperature measurements with infrared thermometers, Agron. J. 59:494-496.

Fuchs, M. and Tanner, C.B. (1966) Infrared thermometry of vegetation, Agron. J. 58:597-601. Jackson, R.D. (1981) Canoṕy temperature and crop water stress. in Advances in Irrigation (D. Hillel, ed.), Academic Press, N.Y., pp.43-85!

Kealy, P.S. and Hook, S.J. (1993) Separating temperature and emissivity in thermal infrared multispectral scanner data: Implications for recovering land surface temperatures, IEEE Trans. Geoscience and Remote Sensing 31:1155-1164.

Nicodemus, F.E. (1965) Directional radiance and emissivity of an opaque surface. Applied Optics 4:767-773.

Nicodemus, F.E., Richmond, J.C., Hsia, J.J., Ginsberg, I.W. and Limperis, T. (1977) Geometrical considerations of nomenclature for reflectance, Nat. Bureau Standards Monograph 160, U.S. Dept. of Commerce, Washington, D.C. 20234. 52pp.

Norman, J.M., Divarkarla, M. and Goel, N.S. (1994) Algorithms for extracting information from remote thermal-IR observations of the earth's surface. Remote Sensing Environment (In Press).

The submitted manuscript has been authored by a contractor of the U.S. Government under Contract No. $\mathrm{DE}-\mathrm{AC} 08-93 \mathrm{NVI} 1265$. ACcordingly, the U.S. Government retains a nonexclusive, royalty-free license to publish or reproduce the published form of this contribution, or allow others to do so, for U.S. Government purposes.

Work supported by the U.S. Department of Energy Nevada Operations office under Contract No. DE-AC08-93NV11265. 
Table 1. Maximum error associated with using the temperature approximations in Eq. (10) versus the black body integrals for 8-14 $\mu \mathrm{m}$ and 10-12 $\mu \mathrm{m}$ wavebands if $\varepsilon_{1}=\varepsilon_{2} . T_{s, 2}-T_{c, 2}$ is the difference between the hemispherical sky temperature and the canopy kinetic temperature. These results are based on all combinations of $T_{s, 1}$ and $T_{s, 2}$ in the ranges $-50 \leq T_{s, 1} \leq-10$ and $0 \leq T_{c, 2} \leq 40$.

$\begin{array}{ccc}\begin{array}{c}\text { Wavelength } \\ \text { band } \\ (\mu \mathrm{m})\end{array} & \text { Emissivity } & \begin{array}{l}\text { Maximum } \\ \text { Emissivity } \\ \text { Error }\end{array} \\ 8-14 & 0.98 & 0.0006 \\ & 0.94 & 0.0019 \\ & 0.90 & 0.0030 \\ 10-12 & 0.98 & 0.0007 \\ & 0.94 & 0.0021 \\ & 0.90 & 0.0032\end{array}$

Table 2. Environmental conditions associated with field measurements of thermal emissivity.

$\begin{array}{llllll}\text { Target } & \mathrm{T}_{\text {sky }}(8-14) & \mathrm{T}_{\text {sky }}(14-22) & \mathrm{T}_{\text {cpy }}(14-22) & \mathrm{T}_{\mathrm{air}} & \mathrm{CO}_{2} \text { Conc. }\end{array}$

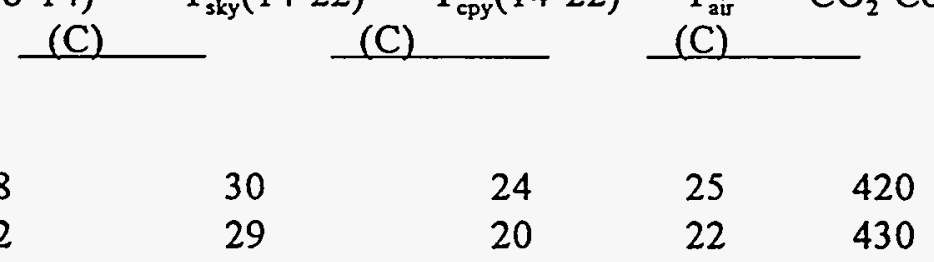

Wheat

$\begin{array}{llllll}\text { Loc. } 1 & -23 & 34 & 26 & 27 & 400 \\ \text { Loc. } 2 & -17 & 31 & 27 & 28 & 400\end{array}$

$\begin{array}{llllll}\text { Soil (Maricopa) } & -22 & 29 & 40 & 31 & 360\end{array}$

$\begin{array}{llllll}\text { Com } & -29 & 13 & 14 & 15 & 450\end{array}$

$\begin{array}{llllll}\text { Soil (Madison) } & -42 & 3 & 5 & 6 & 360\end{array}$ 
Figure 1. Maximum error in canopy emissivity caused by a difference in emissivity of the canopy of 0.01 between 8-14 $\mu \mathrm{m}$ and 14-22 $\mu \mathrm{m}$ wavelength bands. These errors are different for 8-14 $\mu \mathrm{m}$ and 10-12 $\mu \mathrm{m}$ wavelength bands and depend on the temperature difference between the sky and the canopy. The abscissa is the sky temperature in the $8-14 \mu \mathrm{m}$ wavelength band minus the canopy temperature in the 14-22 $\mu \mathrm{m}$ band, and the two curves in each band are for different values of sky temperature in the 14-22 $\mu \mathrm{m}$ minus canopy temperatures in the 14-22 $\mu \mathrm{m}$ bands (DT).

Figure 2. Maximum error in canopy emissivity caused by errors in the measurement of IRT temperatures for the $8-14 \mu \mathrm{m}$ and $10-12 \mu \mathrm{m}$ wavelength bands. The abscissa is the sky temperature in the 8-14 $\mu \mathrm{m}$ wavelength band minus the canopy temperature in the 14-22 $\mu \mathrm{m}$ band, and the two curves in each band are for different values of canopy emissivity in the 8-14 (10-12) $\mu \mathrm{m}$ wavelength band $\left(\varepsilon_{1}\right)$.

$$
i
$$

Figure 3. Maximum error, in canopy emissivity caused by two errors: Measurement errors of IRT temperatures, and a difference of 0.01 in canopy emissivity between 8-14 $\mu \mathrm{m}$ and 14-22 $\mu \mathrm{m}$ wavelength bands. These errors are different for $8-14 \mu \mathrm{m}$ and 10-12 $\mu \mathrm{m}$ wavelength bands and depend on the temperature difference between the sky and the canopy as well as the emissivity of the canopy. The abscissa is the sky temperature in the 8-14 (10-12) $\mu \mathrm{m}$ wavelength band minus the canopy temperature in the 14-22 $\mu \mathrm{m}$ band, and the two curves in each band are for different values of canopy emissivity in the 8-14 (10-12) $\mu \mathrm{m}$ wavelength band $\left(\varepsilon_{1}\right)$. The sky temperature in the 14-22 $\mu \mathrm{m}$ band minus canopy temperature in the $14-22 \mu \mathrm{m}$ band (DT) is $5 \mathrm{C}$.

Figure 4. Brightness temperature of a heated target controlled at $33.0 \mathrm{C}$, as a function of path length between the IRT's and the target, for two IRT's: One sensitive to 8-14 $\mu \mathrm{m}$ and one sensitive to $14-22 \mu \mathrm{m}$. The air temperature is constant at $41.0 \mathrm{C}$ and the $\mathrm{CO}_{2}$ concentration is fixed at $370 \mu \mathrm{mol} \mathrm{mol}^{-1}$.

Figure 5. Relative response of two IRT's to the angle between the centerline of the IRT and a point source of thermal radiation.

Figure 6. Calibration of two IRT's sensitive to the 8-14 $\mu \mathrm{m}$ wavelength band over a wide range of target calibration temperatures with an IRT ambient temperature of $25 \mathrm{C}$.

Figure 7. Directional emissivity of alfalfa and wheat canopies from Maricopa Agricultural Center. The results are the average of two replications for each crop.

Figure 8. Directional emissivity of corn and soil at West Madison Agricultural Farm. The vertical bars are standard deviations and for corn the bold line is adjusted for the path absorption of 14-22 $\mu \mathrm{m}$ radiation by $\mathrm{CO}_{2}$. the corn measurements are an average of eight sets of angular measurements. 


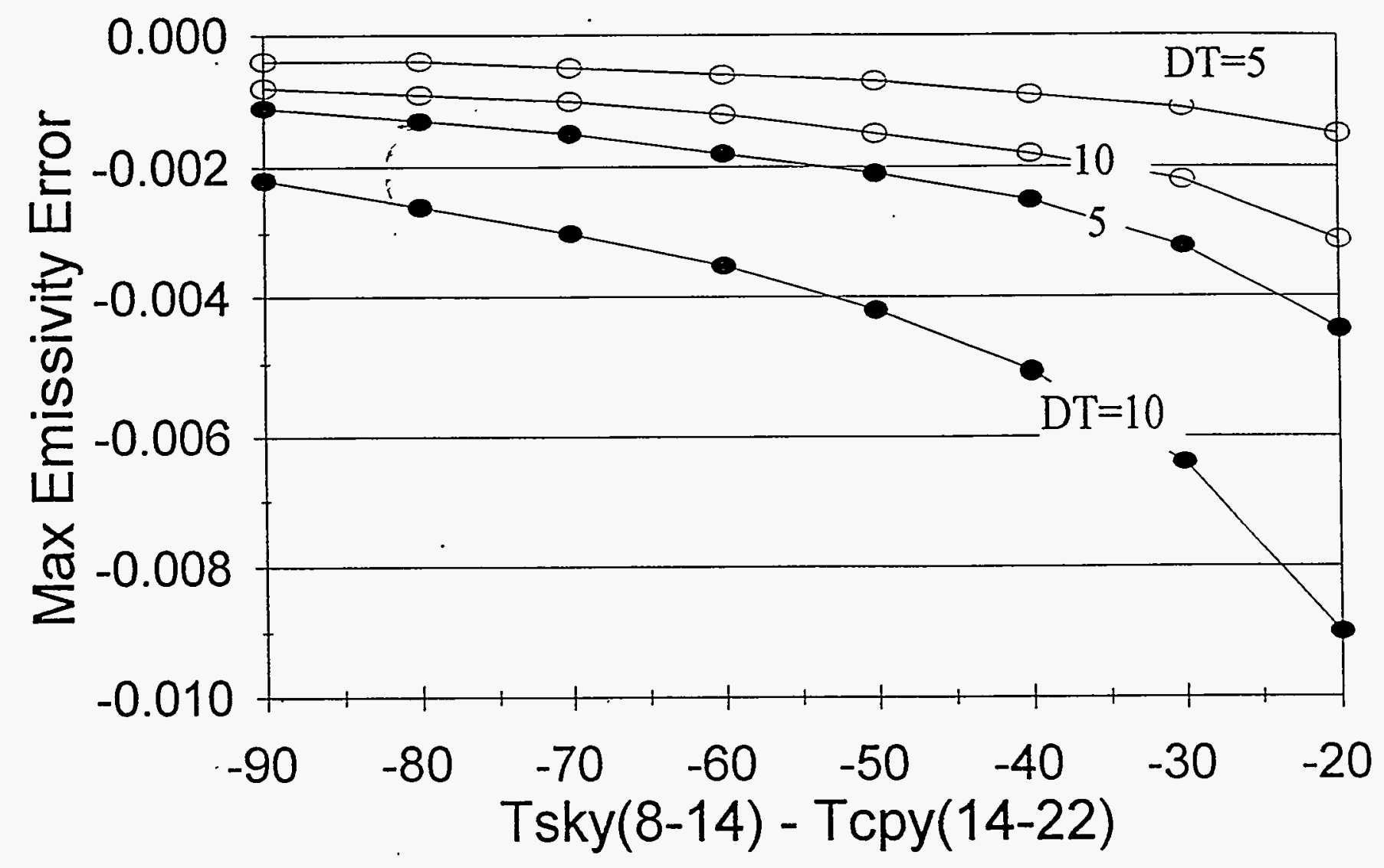

$-10-12$ um $-8-14$ um 


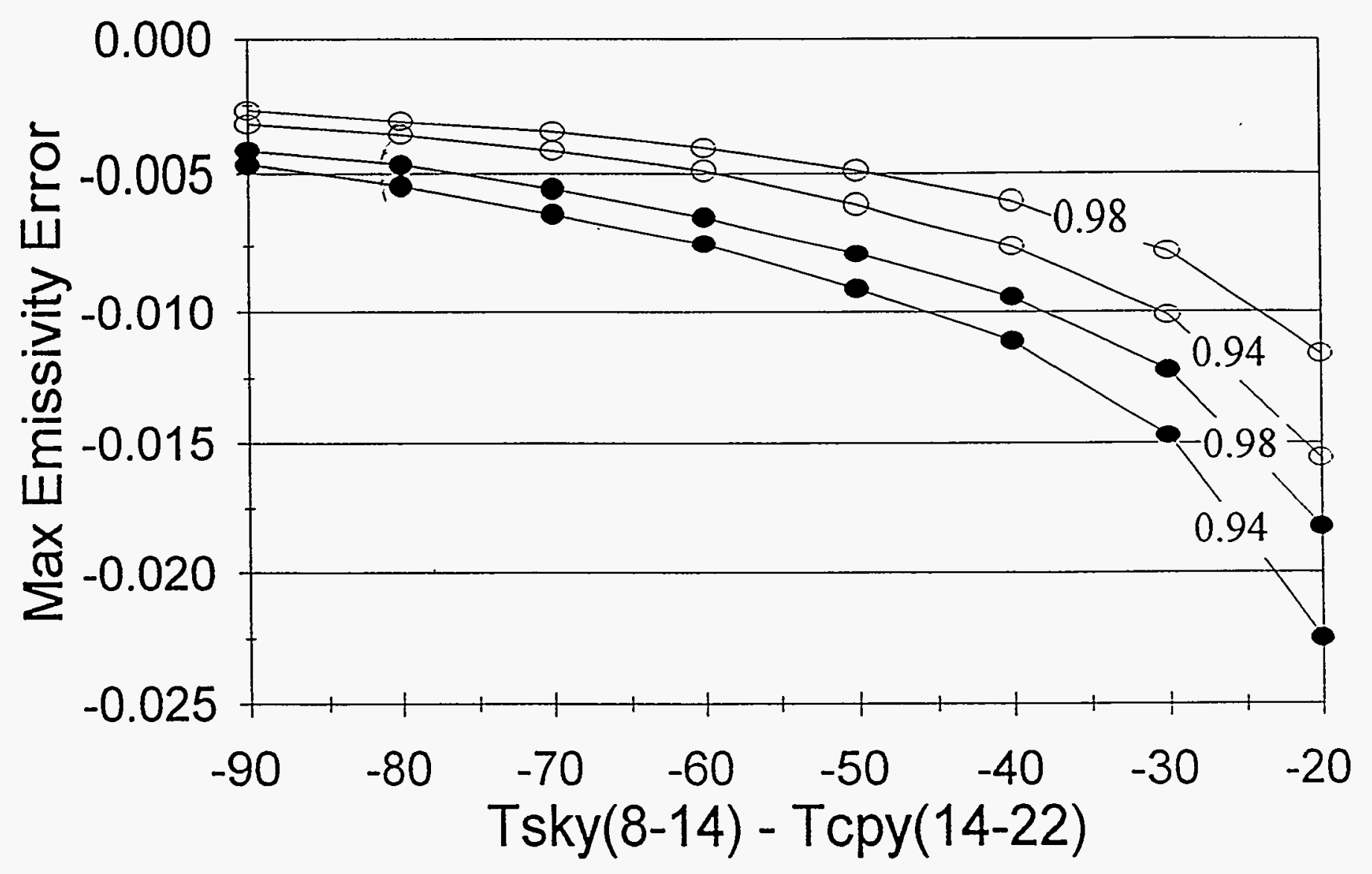

- 8-14 um $-10-12$ um 


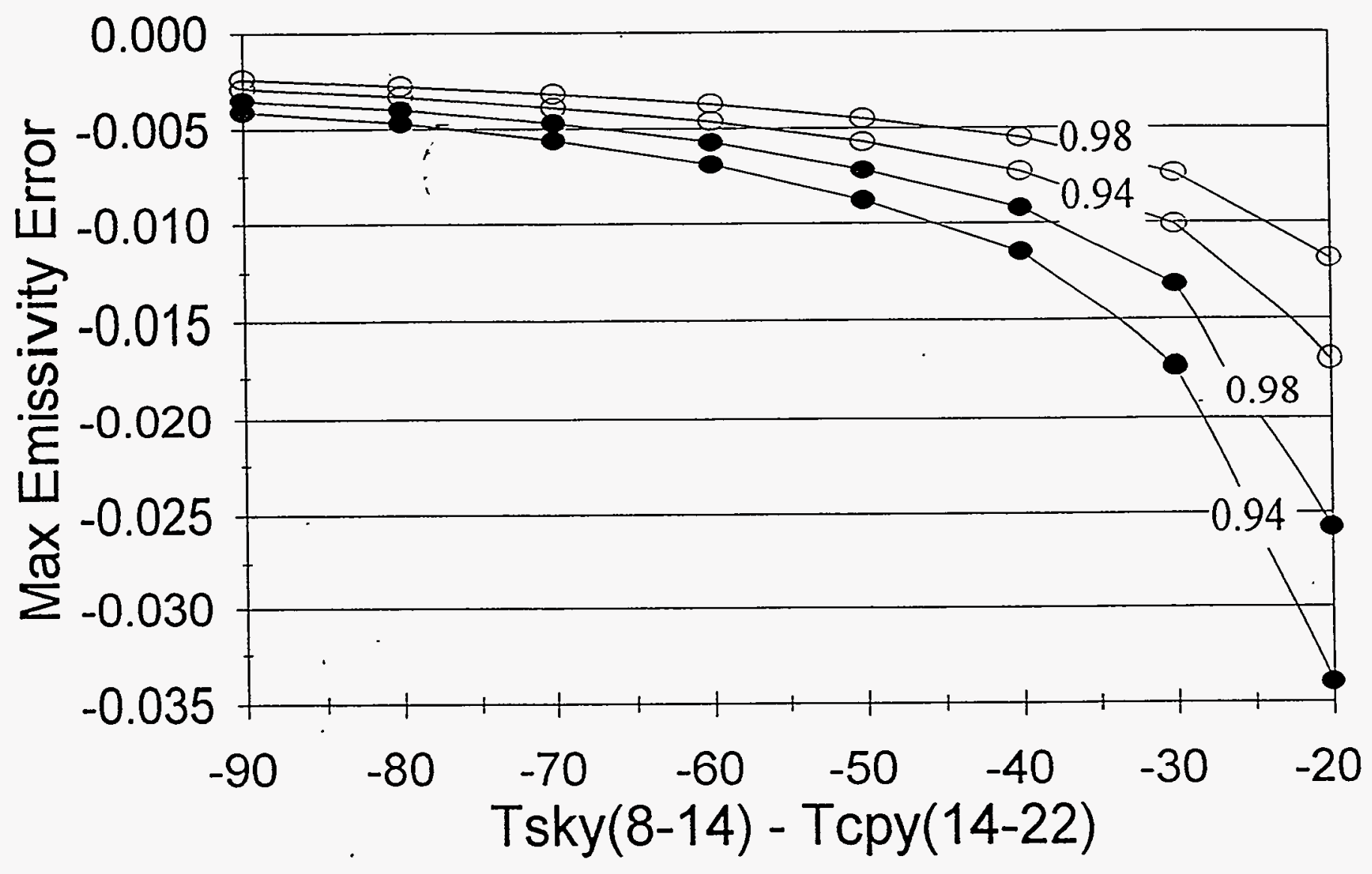

$\leftarrow 8-14$ um $-10-12$ um 


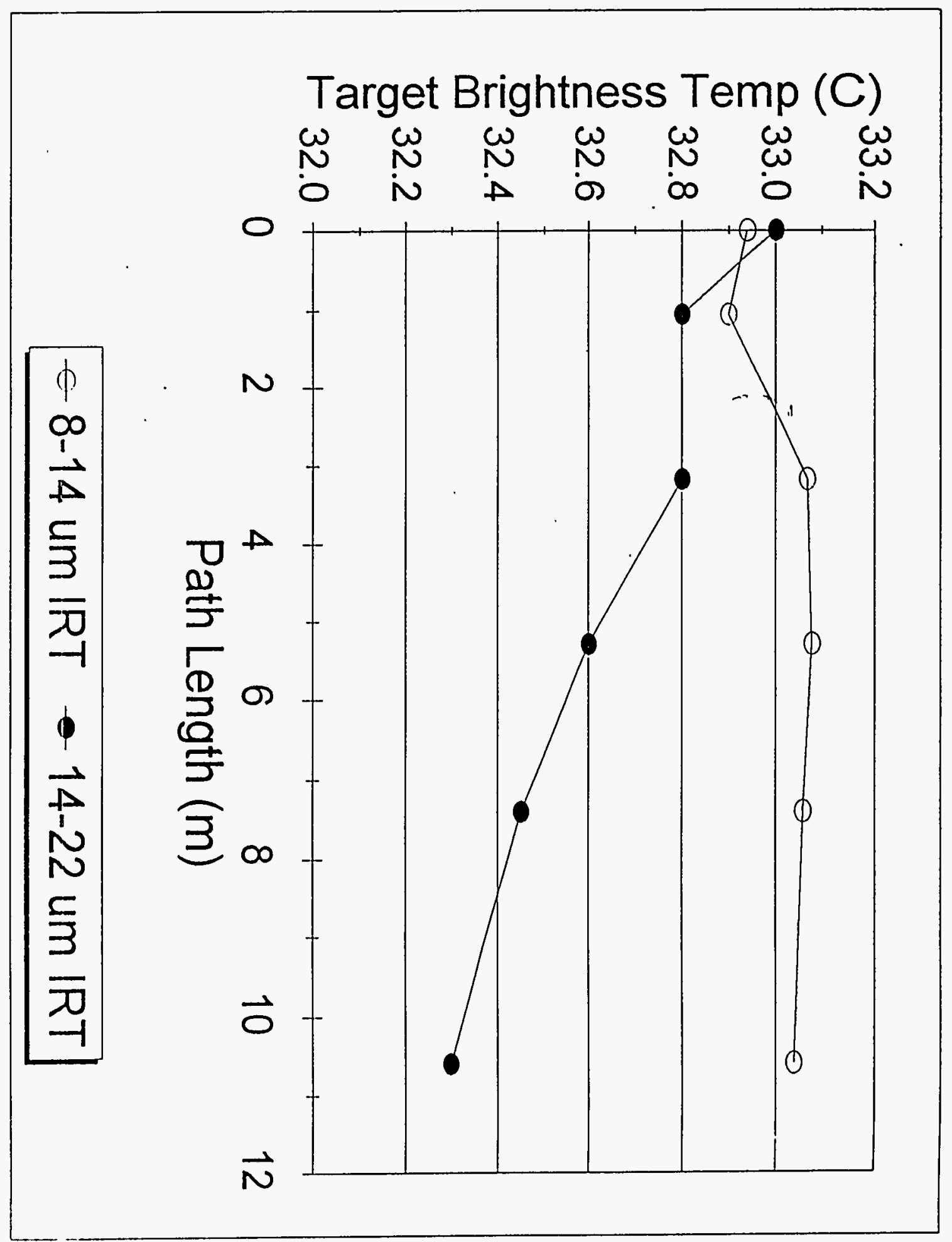




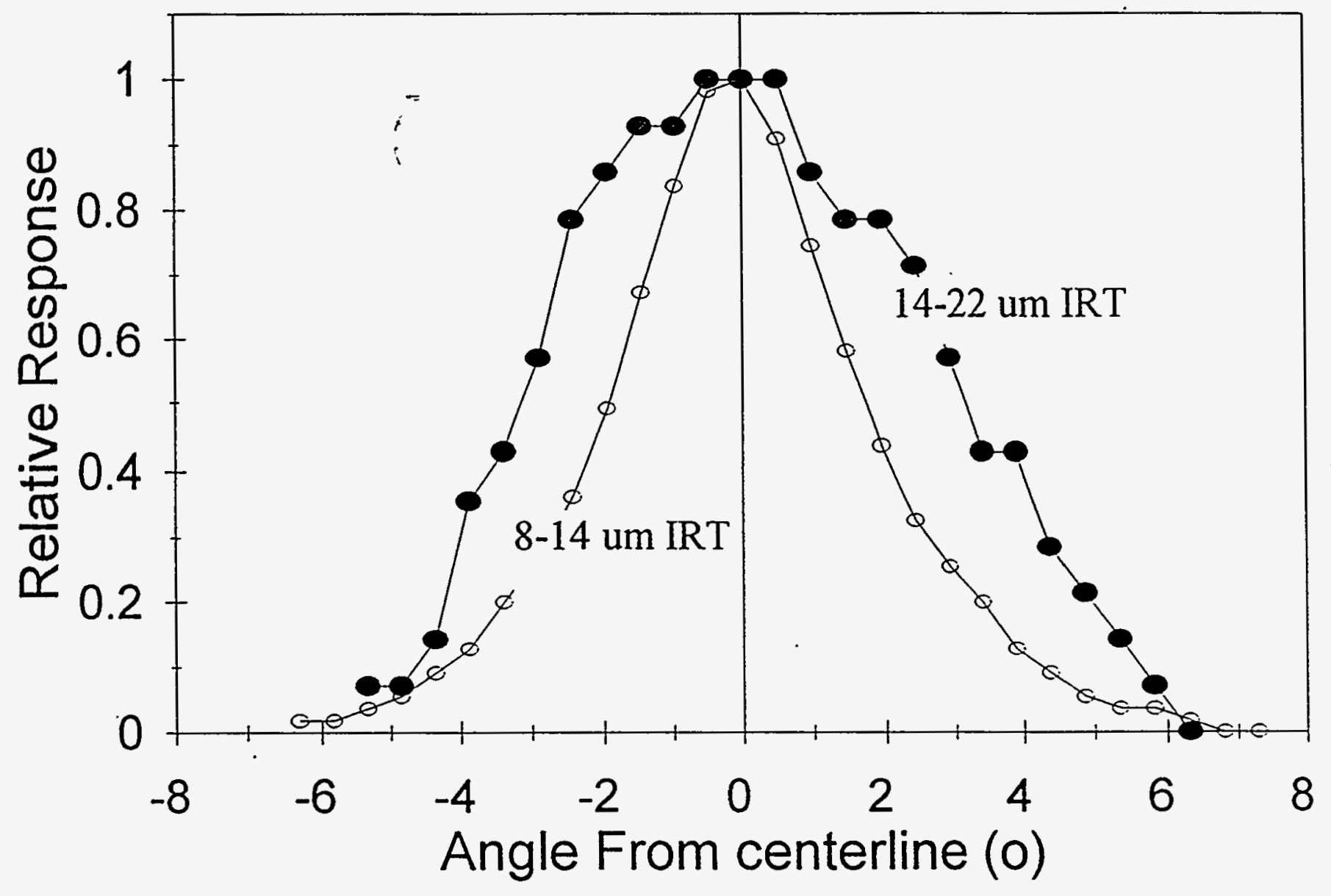




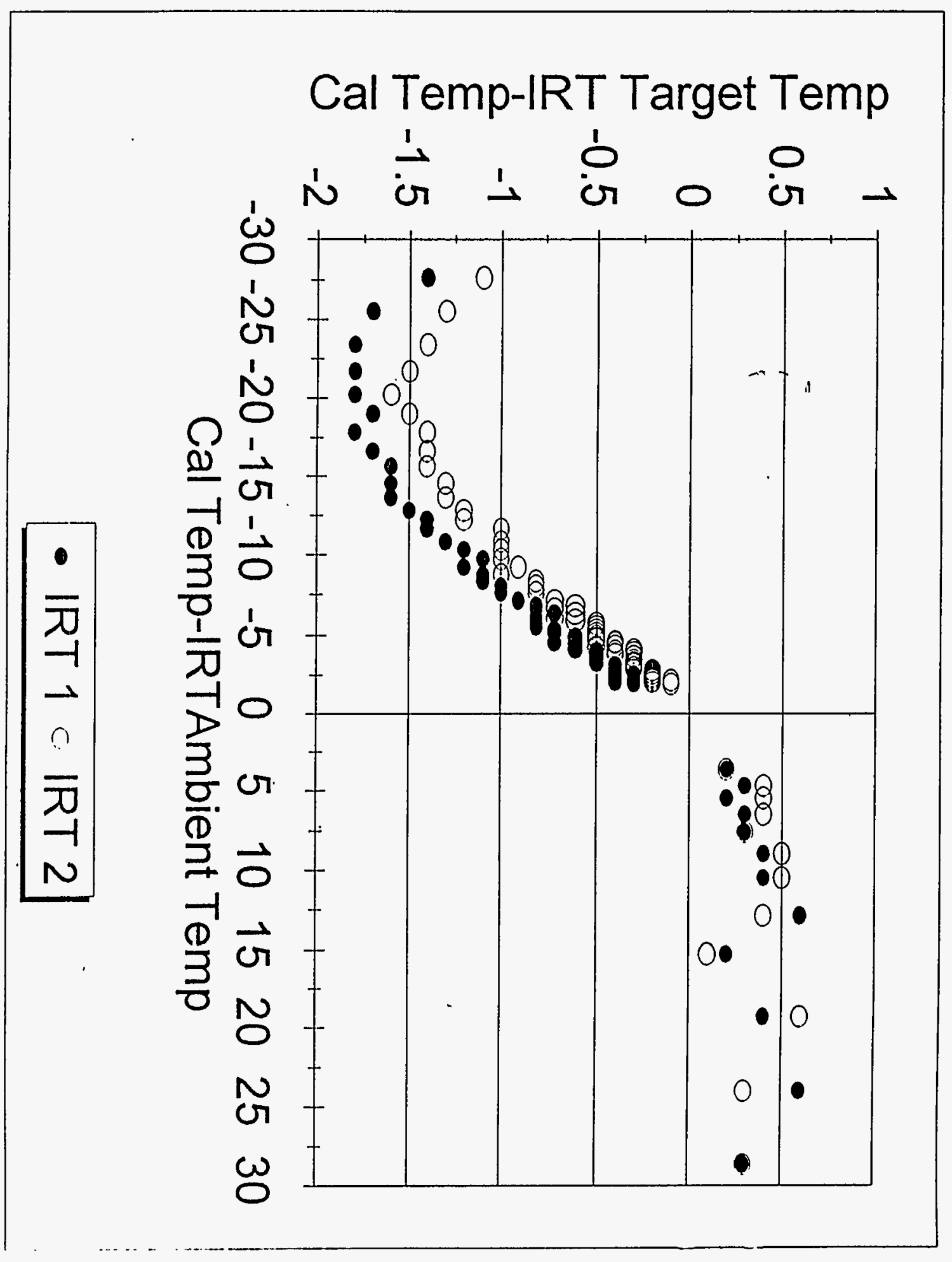




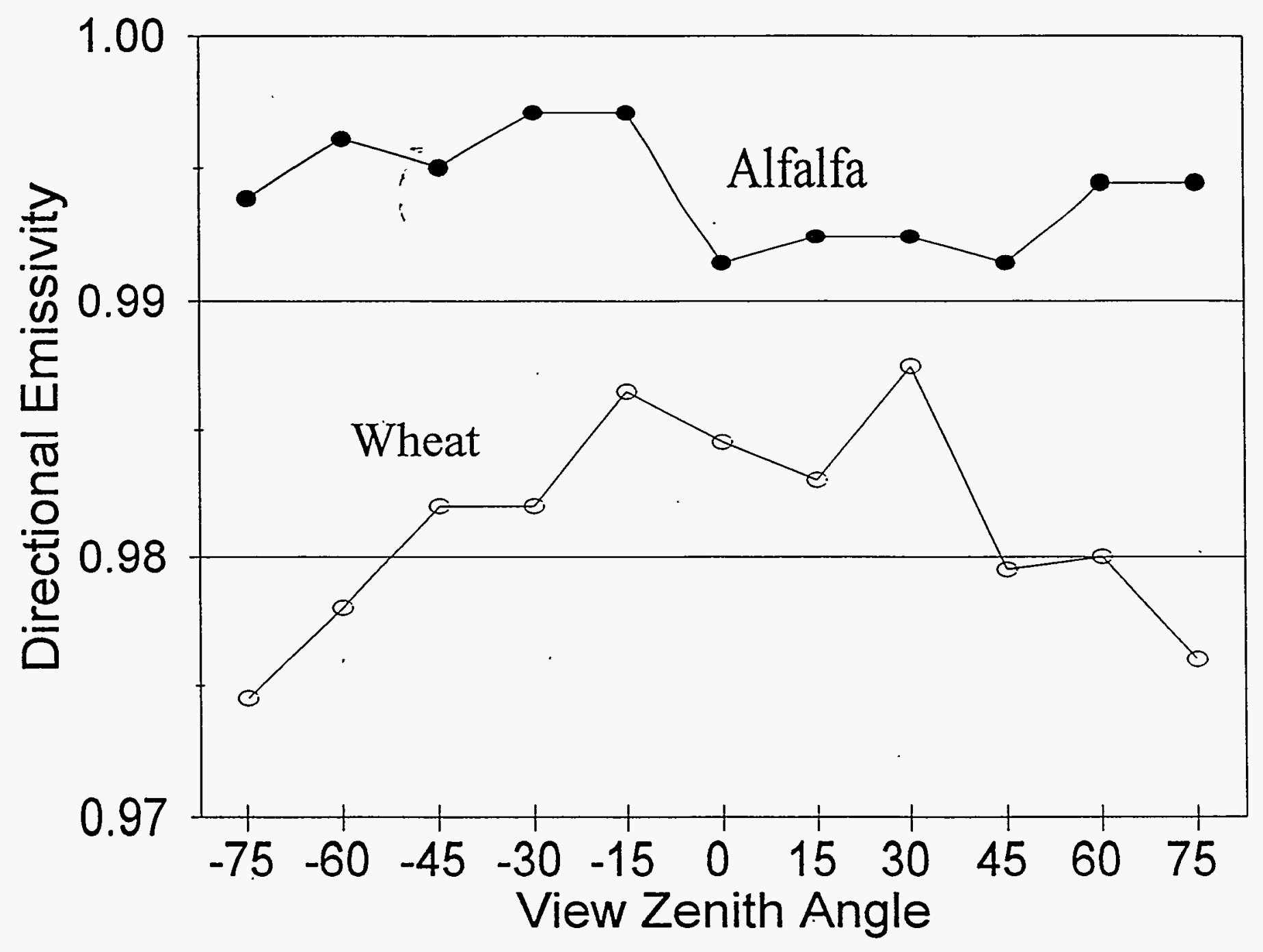




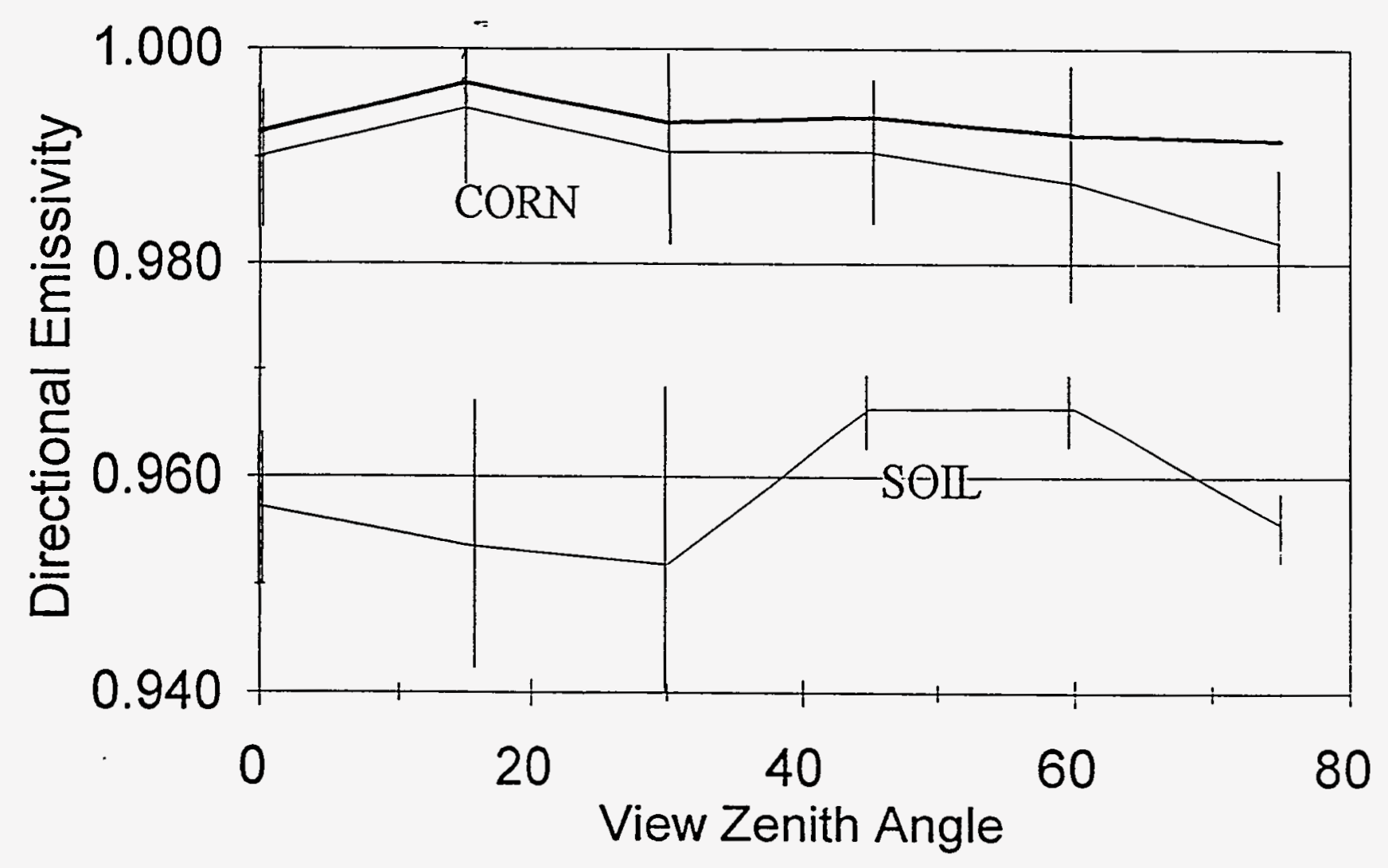

